\title{
Unus non sufficit orbis. Os jesuitas, o mapaemento do mundo e as cartografias periféricas.
}

Uns non suffucit orbis.

The Jesuits, the map of the world and the peripheral cartographies.

\author{
Artur H. Franco Barcelos*
}

Resumo: Houve uma época em que o mundo tinha apenas quatro partes. Ao menos assim acreditavam os europeus a partir do século XVI. A Europa, a Ásia e a África eram as três partes que mundo sempre tivera, desde a criação. A partir de 1492 o que era dúvida virou certeza, havia uma quarta parte. A América entrava assim na geografia mundo dos europeus. E na geografia sagrada. Era preciso explicar esse Novo Mundo, sua flora, sua fauna e seus habitantes. Entre os mais dedicados a fazê-lo estiveram os jesuítas. Primeiro, descrevendo esse grande mundo, para onde acorreram como missionários. Depois, detalhando suas regiões e povos. Surge daí uma vasta cartografia e a ideía de que um mundo só não era suficiente para as conquistas espirituais feitas em nome de Deus.

Palavras chave: Jesuítas, Cartografia, Missões.

Abstract: There was a time when the world had only four parts. At least so Europeans believed from the sixteenth century. Europe, Asia, and Africa were the three parts the

\footnotetext{
* Professor da Universidade Federal do Rio Grande - FURG, Rio Grande, Brasil. E-mail: ahbarcelos@hotmail.com
}

64 Artur H. Franco Barcelos. Unus non sufficit orbis. Os jesuitas, o mapaemento ... 64-83. 
world had always had since creation. From 1492 what was doubt became certain, there was a fourth part. America thus entered the geography of the world of Europeans. And in sacred geography. It was necessary to explain this New World, its flora, its fauna and its inhabitants. Among the most dedicated to do so were the Jesuits. First, describing this great world, where they went as missionaries. Then detailing their regions and peoples. There arises a vast cartography and the idea that a world alone was not enough for the spiritual achievements made in the name of God.

Key words: Jesuits, Cartography, Missions.

Recibido: 23 de octubre de 2016

Evaluado: 8 de diciembre de 2016 
Conta a lenda que, quando terminou a criação, Tupã, uma das divindades guarani, chamou a Guarán para que fosse encarregado do Gran Chaco. Guarán assumiu com eficiência seu trabalho e tratou das matas, da terra, da fauna e da flora, bem como do povo que ali colocara Tupã. Cerca de sua morte, Guarán entregou sua missão a seus dois filhos, Tuvichavé, o mais velho, e Michiveva, o menor. Tuvichavé era mais nervoso, decidido e enérgico, enquanto Michiveva era tranquilo e pacífico. Destas diferenças resultaram opiniões distintas de como administrar o Gran Chaco. Añá, o maligno, se valeu da situação para fazer das suas. Convenceu aos dois irmãos de que deveriam resolver suas diferenças em uma disputa de destrezas. Aceito o desafio, foram os dois para o alto dos cerros que circundam o Gran Chaco. Entre as provas que acordaram realizar, estava a destreza com arcos e flechas. Michiveva lançou em uma árvore distante, seguro de que o fazia com perfeição. Mas Añá, que tudo já havia planejado, a desviou, fazendo com que penetrara no coração de Tuvichavé. O sangue escorreu pelo cerro e chegou até o Chaco. Com sua força, abriu um caminho vermelho no solo, que formou o I-phytá, o Bermejo. Michiveva, quando soube o que havia feito, caiu em um pranto interminável. Suas lágrimas também seguiram o mesmo rumo do sangue de seu irmão, indo formar outro rasgo na terra, justo ao lado do I-phytá. Nascia o Pilcomayo, que até hoje corre ao lado do Bermejo ${ }^{1}$. Os guarani caminhavam seguros, com seus pés nus sobre a terra, pois sabiam de onde vinham aquelas águas, qual havia sido sua origem e, ao olhar para elas, podiam igualmente pensar na dissidia, na discórdia, na desunião. Mas não sabiam que, quilômetros dali, outros homens viriam de outros rios, de outras águas, de outras terras, para falar de outro mundo, de outro deus.

Quando os missionários da Companhia de Jesus chegaram à América, na metade do século XVI, via Brasil português, encontraram uma grande variedade de crenças e manifestações espirituais entre os indígenas, as quais foram sendo conhecidas na medida em que mais jesuítas chegavam ao "Novo Mundo" e se espalhavam pelo continente. Desde o extremo Norte, na Nouvelle France, até a Tierra del Fuego. Esta diversidade significava também as distintas maneiras como os indígenas explicavam o mundo, sua origem e sua história. Demonstrava, igualmente, suas formas de significação da geografia e seus elementos concretos, como montanhas, vales, rios, lagos, matas, bosques, desertos, florestas, geleiras, etc. Frente a estas realidades, os inacianos impuseram, lentamente, sua visão de mundo, cristã, católica, universalista e uniforme tanto da história quanto da geografia. Entre as mudanças propostas pelos europeus, estavam as formas de representação gráfica do mundo físico que, assim como as histórias e crenças, eram distintas daquelas praticadas por indígenas. E mesmo aqueles que, nascidos na América, tiveram sua formação em colégios e universidades estabelecidas, entre outros, pelos jesuítas, formaram sua visão de mundo nas matrizes judaico-cristã e greco-romana dos europeus. É assim que, paulatinamente, o conhecimento geográfico que os europeus formam sobre a América se desenvolve, enquanto as possíveis práticas indígenas de reconhecimento, descrição e interpretação dos fenômenos geográficos, sociais e históricos incluídos, vão sumindo nas caixas do esquecimento forçado. Era preciso colonizar o espaço e colonizar o tempo. Inculcar outro mundo neste mundo. E fazer de todos, um único mundo. Visível, palpável, conhecido e localizado. E para isto, muito contribuiu a ação dos jesuítas, posto que, entre os homens da Igreja católica em particular, e entre os europeus em geral, foram eles os mais destacados na exploração combinada com descrições, classificações e

\footnotetext{
${ }^{1}$ Parodi, 2005.
} 
interpretações dos elementos da geografia americana por pelo menos 200 anos. E entre os resultados de seus olhares sobre a América emerge uma cartografia numerosa e expressiva.

Esta ação de desestruturação do mundo indígena americano, que se dá em todas as facetas da vida destas populações, não é um movimento isolado, promovido pelos jesuítas apenas em suas missões americanas. Faz parte de um movimento muito mais amplo, que coloca os jesuítas no olho do furacão da modernidade, cuja consolidação ocorre no mesmo tempo de vida da Companhia de Jesus, entre os séculos XVI e XVIII. E é ai, neste topos que se deve encontrar os inacianos e sua "obra", glorificada pelos próprios e por um sem número de historiadores nos dois séculos seguintes. Quando se insere a Companhia de Jesus no contexto mais amplo da modernidade, como muitos autores já fizeram, se pode então perceber seus movimentos em todas as direções que os ventos modernos soprassem. Neste sentido, vemos que os jesuítas também foram partícipes de todas as transformações transcorridas naqueles intensos 300 anos da Era Moderna.

Os primeiros anos foram dedicados a sentar as bases da Companhia na Europa, através da rede de colégios e da inserção gradual nos círculos de poder ${ }^{2}$. Mas foram também os anos do início da "mundialização" da ordem. De 1539 até o final do século XVI, os jesuítas construirão seus primeiros ícones, Inácio de Loyola, o fundador e primeiro Padre Geral até 1556, e os Padre Francisco Xavier, José de Anchieta, e André de Oviedo. Os quatro ilustres do mapa Societas Iesu per universum mundum diffusa praedicat Christi evangelium, que Heinrich Scherer publicou em seu Atlas Novus, parte II, Geographica Hierarchia, em 1700 e do qual se fará referência adiante. Concretizada a etapa europeia e colhendo os primeiros frutos, bem como os primeiros percalços, das missões na Ásia, América e África, os jesuítas assistem a formação da União Ibérica, com Felipe II ostentando as coroas de Espanha e Portugal. É o início da Monarquia Católica e sua projeção em escala planetária, como aponta Serge Gruzinki.3 No âmbito da Monarquia Católica, os jesuítas mover-se-ão pelas "quatro partes" do mundo4, em alguns casos trilhando o rastro de beneditinos, agostinianos, franciscanos e mercedários, em outros sendo os primeiros a travar contatos evangelizadores com populações não europeias5. Seguiam aquela consigna presente na fórmula esboçada por Loyola em 1538:

[...] ir sem demora para qualquer região aonde nos quiserem mandar, sem qualquer subterfúgio ou escusa, quer nos enviem para entre os turcos ou outros infiéis, que habitam mesmo que seja as regiões que chamam Índias, quer para entre hereges ou cismáticos, quer ainda para junto de quaisquer fiéis. 6

Espalham-se. Agrupam-se em torno de Residências, Casas Professas e Colégios. Penetram nos interiores, cruzam desertos, sobem colinas e montanhas, embrenham-se nas matas e florestas, navegam em canoas e pirogas, por rios, arroios e igarapés. As

\footnotetext{
${ }^{2}$ Laucouture, 1994; O’Malley, 2004; Wright, 2006.

${ }^{3}$ Gruzinski, 2001: 178.

${ }^{4}$ Ibíd, 2010.

${ }^{5}$ Boxer, 2007; Barnadas, 1997: 522-523.

${ }^{6}$ Loyola, 1997: 25.
} 
vezes desaparecem. Por semanas, meses. O que os mantém em relativa coesão? Papéis. Muitos papéis. A forma de texto epistolar foi uma constante durante toda a permanência dos jesuítas na Ásia, na África e na América. Desde a criação da ordem a prática epistolar fora implementada como uma necessidade administrativa. À medida que os missionários passaram a áreas tão distantes da Europa como Goa e o Brasil, esta necessidade aumentava significativamente. Antes mesmo da chegada dos jesuítas ao Brasil, em 1549, o padre Juan Polanco, secretário da ordem, expediu um comunicado a todos os membros onde explicava as razões da manutenção de um intercâmbio de correspondências pelos inacianos. Esta prática contribuiria para a unidade dos membros da ordem e sua administração; auxiliaria na atração de novos candidatos para a Companhia de Jesus e na captação de recursos com benfeitores; e também reforçaria as vocações individuais através da divulgação dos atos de seus irmãos ${ }^{7}$.

Esta práxis resultou em uma produção textual robusta, composta por espécies documentais diversas. Cartas, relatos, diários, informes, instruções, atas, crônicas, histórias naturais, etc. ${ }^{8}$ Não apenas a produção de textos foi uma constante desde os primeiros anos da ordem, mas também sua circulação, tanto no âmbito interno da Companhia, quanto para um público mais amplo que tinha acesso a parte dela através de publicações. Assim, dispersos, os jesuítas não estão isolados. A correspondência oficial e aquela de caráter privado os mantém em contato. Os papéis vão e vem, circulando por quatro continentes, tendo Roma como um centro de articulação. Logicamente que as distâncias são uma dificuldade a ser enfrentada. As vezes, solitários em uma missão recôndita do ponto de vista de Roma, os contatos serão esparsos, mas ocorrerão.

De cada lugar chegavam os pedaços de uma narrativa que foi sendo moldada. Uma narrativa do mundo. E uma narrativa da Companhia de Jesus neste mundo. Mas nem só de palavras se constrói uma narrativa. São necessárias imagens. E neste particular, novamente a Companhia de Jesus vai apresentar um diferencial em comparação com suas congêneres evangelizadoras. Da profusão de imagens produzidas por jesuítas nas quatro partes do mundo dão conta os numerosos acervos que se conhece desde a época em que circulavam pelos ambientes eclesiásticos, políticos e científicos, passando por sua reorganização em acervos de bibliotecas, arquivos, museus, universidades, coleções particulares, entre outros, do século XIX até os dias atuais. E ainda voltam a aparecer quando um documento inédito é localizado, identificado e publicizado. E neste vasto campo imagético estão os mapas. Em uma quantidade expressiva. Para além desta quantidade, que por si já denota uma marca distintiva da produção de registros por parte do inacianos, está a qualidade e detalhamento das mais variadas informações, bem como a dimensão espacial que cobrem, isolados ou em conjunto.

Tal como os documentos escritos, que possuem uma grande diversidade de formas e funções, também os mapas jesuíticos apresentam uma variada gama de estilos, temas, processos de produção e finalidades. Em que peses esta miscelânea, é possível ver estes mapas em conjunto, como um corpus documental que possui uma unidade. A unidade da narrativa visual do mundo que os jesuítas acreditavam estar descortinando para os seus contemporâneos. E da narrativa visual da história que a própria Companhia de Jesus criava sobre si, projetando sua imagem para os demais. Para se perceber o

\footnotetext{
${ }^{7}$ Eisenberg, 2000: 50 .

${ }^{8}$ Sobre a produção textual jesuítica e suas relações com a geografia e o espaço ver Barcelos, 2013.
} 
papel que as imagens jogam na construção desta narrativa basta com recorrer a dois exemplos. Um que se esboça na metade do século XVII e outro na abertura do século XVIII. De um lado, uma obra que celebra o primeiro centenário da Companhia de Jesus. De outro, um Atlas do mundo, com o fôlego de vários volumes. Em ambos, as pretensões mundiais da Companhia. Seu caráter universal e universalizante. E o recurso a imagem, ao mapa, ao mundo explorado, reconhecido, medido e decifrado pelos inacianos, ao menos de seu ponto de vista.

Em 1640 a Companhia de Jesus chegava aos 100 anos de existência. Em uma ordem tão marcada pelo zelo de sua imagem e prestígio, é normal que se apresente o ensejo para traduzir sua obra em algo palpável, para consumo interno e projeção externa. Todas as Províncias da Companhia foram convidadas a participar deste empreendimento. E o resultado foi o livro Imago primi saeculi Societatis Iesu a Prouincia Flandro-Belgica euisdem Societatis repreasentata.9 Embora a autoria seja atribuída a Ioannes Bollandus, trata-se de uma obra coletiva. Com mais de 900 páginas, o Imago Primi Saeculi se destaca também por seus 126 emblemas. O emblema é uma forma literária e visual que combina um lema com uma imagem e um poema breve. Assim como a maior parte do conteúdo textual do Imago Primi, os emblemas também são anônimos ${ }^{10}$. Segundo Patricia W. Manning, isto se deve a intenção de passar a ideia de um trabalho coletivo da Companhia, que se sobrepõe a individualidade de seus membros. ${ }^{11}$ O livro está dividido em seis partes ou capítulos. Societas nascens (o nascimento da Companhia) com 31 emblemas; Societas crescens (o crescimento da Companhia) com 14 emblemas; Societas agens (as ações da Companhia) com 8 emblemas; Societas patiens (os sofrimentos da Companhia) com 17 emblemas; Societas honorata (as honrarias da Companhia) com 14 emblemas; e a última parte dedicada a descrição da Companhia na Província Flamenca, com 14 emblemas. Estruturada desta forma, a obra emula a vida de uma pessoa, com as etapas percorridas até a salvação.

Na segunda parte, Societas crescens, destaca-se um emblema [Fig.01] que se faz acompanhar pelo lema Unus non sufficit orbis, "Um mundo só não basta". A ilustração trás o deus Eros menino entre dois hemisférios que incluem, de uma lado a América e o oceano Pacífico, e de outro a África, a Ásia e o oceano Índico. Eros sustenta um arco em uma mão e uma flecha em outra. Sobre a ilustração está a frase Societatis Misiones Indicae, em uma alusão as missão às Índias, que a julgar pelas áreas destacadas nos mapas dos hemisférios, seriam tanto as Índias Orientais, quanto as Índias Ocidentais. Abaixo da ilustração está o lema já referido. Segundo as interpretações correntes acerca deste lema, é uma referência à um trecho da Sátira X, de Decimus Iunius Iuuenalis, Juvenal (I d.C.). No original, Juvenal trata de Alexandre, o Grande, e suas conquistas, para o qual um mundo só não seria o bastante: Unus Pellaeo Iuvenis non sufficit orbis. Todo o Imago primi é permeado de excertos de poemas latinos, com passagens também em grego e hebreu. A obra é uma opulência da erudição jesuítica. Este emblema em particular, colocado na parte que trata da expansão e crescimento da Companhia de Jesus, vai buscar em Juvenal a forma de se reportar a Alexandre e suas conquistas, finalizadas na Índia. Assim, os jesuítas demonstram aos seus leitores que podem ir além

\footnotetext{
${ }^{9}$ Bollandus, 1640 .

${ }^{10}$ A obra foi editada em latim e flamenco e das 126 ilustrações se conhecem apenas os autores dos frontispícios, que incluem as assinaturas de Philipp Frutiers, Abraham Diepenbeeck, Cornellis Galle e Michael Natali.

${ }^{11}$ Manning, 2007: 218.
} 
de Alexandre. Também aludem ao fato de que o "Velho Mundo" não é mais suficiente. É preciso ir aos "Novos Mundos", especificamente à América e a Ásia, destacadas nos hemisférios. Imagem e texto jogam aqui com a ampliação do mundo através da ação dos jesuítas. O lema passou a encarnar o espírito da empresa mundial jesuítica, sendo utilizado em várias ocasiões posteriores. Chegou-se mesmo a dizer que as velas do navio que levou Manuel da Nóbrega ao Brasil continham esta frase12.

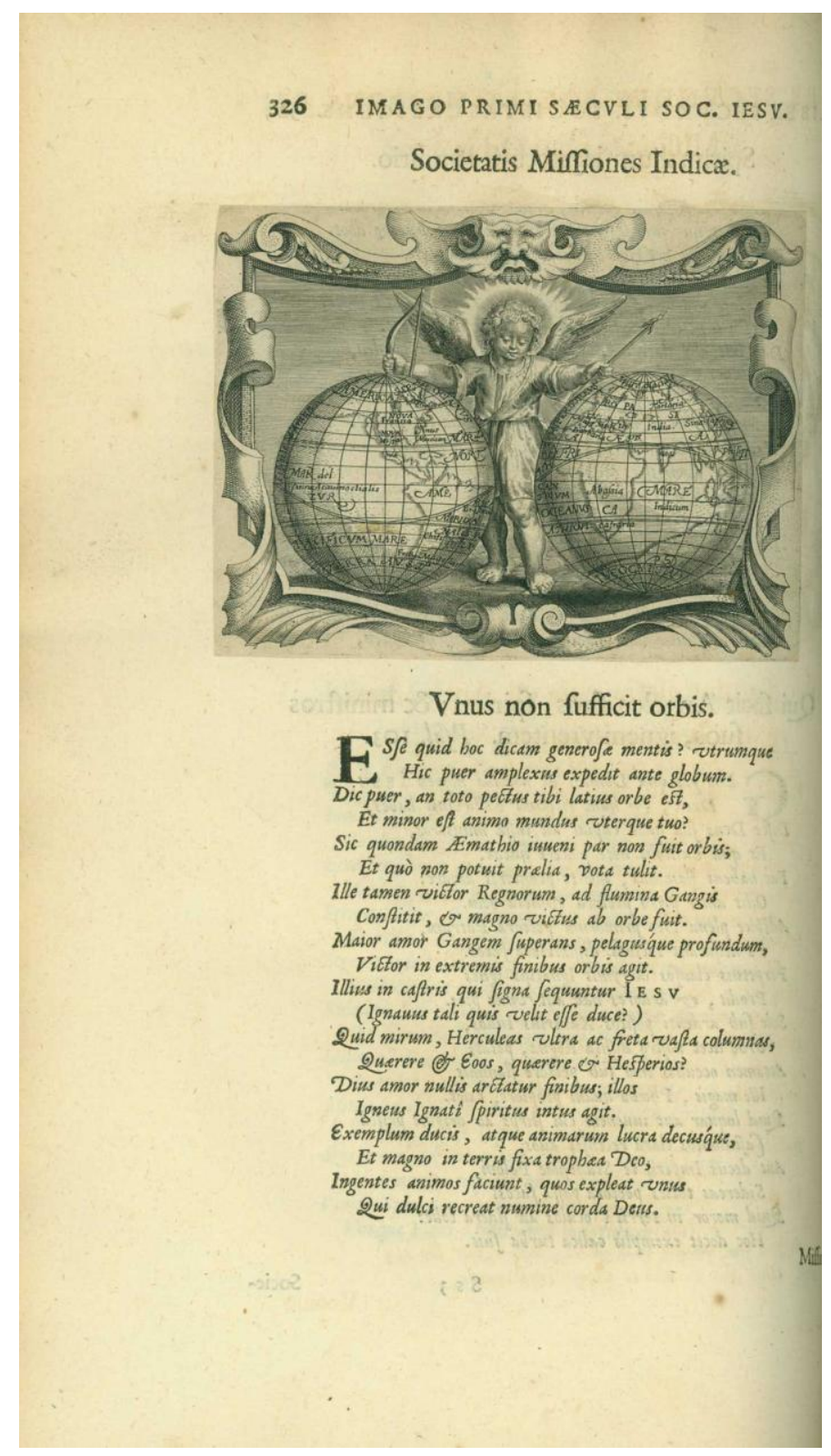

Fig. 1: Emblema da Imago Primi Saeculi

12 De fato, no frontispício do livro História da Companhia de Jesus no Brasil, do Padre Simão de Vasconcelos (1663), há uma gravura de Albert Clowet [Fig.2] onde consta um Galeão com as velas enfunadas e o lema do Imago Primi Saeculi. Obviamente, uma representação inspirada pela Imago e a idéia da expansão mundial da Companhia. Ver Domingues, 1999: 105-139 
Sessenta anos após a edição do Imago Primi, a realidade da Companhia já era outra em termos de sua expansão mundial. No extremo da Ásia, a missão japonesa há muito havia fracassado. Em 1639 os jesuítas encerraram de forma dramática sua presença, em meio as profundas mudanças na política local13. Na Etiópia, desde 1632, os jesuítas já não estavam mais autorizados a evangelizar, após sofrerem, assim como no Japão, uma severa repressão14. Apenas na China e na América as coisas pareciam estar em marcha. Em que pese o fato de que na China a controvérsia dos ritos e as disputas internas entre jesuítas franceses e portugueses gerassem alguns problemas graves15. Destes cenários díspares, a América parecia o mais promissor nos anos que transcorreram entre 1640 e 1700 . Havia 8 Províncias estabelecidas e novas frentes de evangelização se abriam ao Sul e ao Norte do continente. Pode-se dizer que, na virada do século XVII para o XVIII a Companhia de Jesus havia alcançado o auge de seu "raio de ação". Dali para frente, apesar de alguns avanços importantes em termos de áreas alcançadas pela evangelização jesuítica, os anos seriam de disputas amargas, reveses e, finalmente, a expulsão dos territórios portugueses (1759) e espanhóis (1767) até a supressão de 1773. Portanto, o início dos setecentos parece ser outro destes momentos em que a Companhia pode demonstrar sua pujança e alcance. E o fará através de um de seus membros, versado em cartografia. E o fará através de imagens. Mais precisamente, através de um Atlas. O Atlas Novus do Padre Heinrich Scherer16.

O Atlas Novus é uma obra de fôlego, com 7 volumes, editados entre 1702 e 1710. E reeditados entre 1730 e 1737. Os sete volumes são Geographia Naturalis, Geographia Hierarchica, Geographia Politica, Tabellae Geographicae, Atlas Marianus, Critica Quadrapartita, e Geographia Artificialis. Heinrich Scherer lecionou hebraico, matemática e ética em Dillingen. Foi Tutor dos Príncipes de Mantua e Baviera. Era o protótipo dos jesuíta que compunham a elite intelectual da ordem e penetravam nos círculos de poder. Seu Atlas Novus está composto de 180 mapas, divididos nos 7 volumes. Dentre estes mapas, destaca-se Societas Iesu Per universum mundum diffusa Praedicat Christi Evangelium [Fig.2]. Trata-se de um mapa do "mundo" com características absolutamente peculiares que apontam para uma concepção do lugar-mundo da Companhia de Jesus por volta do ano de 1700. Nele, Scherer apresenta sua visão sobre a projeção, o alcance e dimensão que as missões jesuíticas haviam obtido. Ao contrário dos Mapa Mundi, popularizados a partir da instituição da Projeção de Marcator, no século XVI, o mapa de Scherer não apresenta a Europa ocupando um lugar central, mas sim uma Projeção Polar, centralizada no Polo Norte. Este deslocamento é parte da estratégia de Scherer de transformar seu Atlas em um veículo de divulgação da Companhia de Jesus e sua obra terrenal. O Polo Norte de Scherer é um lugar vazio. Isto não significa que Scherer ignorasse a existência de porções das massas de gelo desta parte do mundo. Em sua época, as extremidades das geleiras já haviam sido reconhecidas. Mas sua intenção não é a de um mapeamento desta região. O que busca é um deslocamento do olhar. Ao colocar as quatro partes do mundo nesta projeção, a Europa perde sua centralidade. Estaria Scherer igualando realidades distintas? Certamente não. No Atlas há ainda mais dois mapas onde a Projeção Polar é utilizada. São eles o Reprasentatio geographica itineris maritimi navis

\footnotetext{
${ }^{13}$ Brasil de Sá, 2014: 252-265.

${ }^{14}$ Cohen Shabot e Martínez D’alòs-Moner, 2006: 190-212.

${ }^{15}$ Diaz de Seabra, 2011. 417-424.

${ }^{16}$ Scherer, 1702-1710.
} 
Victoria in qua ex personis CCXXXVII finita navigatione rediere tantum XVIII quae solo indusio tectoe et faces accensas manibus praferentes in basilica hispalensi se voto exsolverunt VII Sept. ann. MDXXII, que apresenta a rota da viagem de circunavegação de Fernão de Magalhães, entre 1519 e 1522, que terminaria com o retorno de apenas uma embarcação e 18 sobreviventes, entre os quais não estava Magalhães, morto em 1521, no arquipélago de Guam; e o Imago Totius Orbis Terraquei cum suo Apparatu ab Auctore Naturae in Suas Partes Distributi Geographic Exhibita. Neste, o mapa base é o mesmo dos anteriores. Porém, suas alegorias "contam" uma narrativa das lutas terrenas travadas pelo catolicismo e protagonizadas pelos jesuítas, contra as forças do mal. E o anúncio da preparação para a segunda vinda de Cristo $^{17}$.

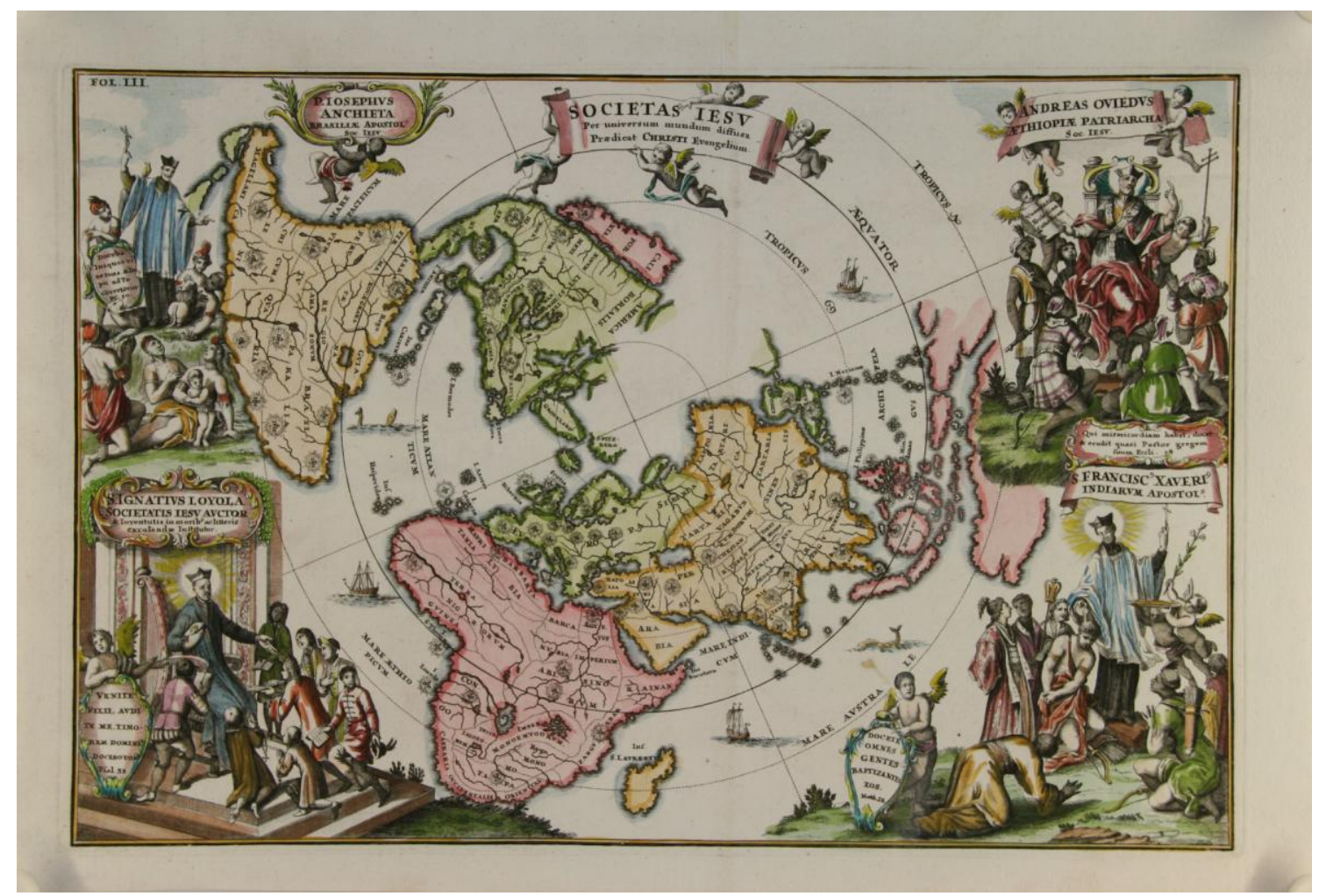

Fig. 2: Societas Iesu Per universum mundum diffusa Praedicat Christi Evangelium. Heinrich Scherer, Atlas Novus, 1702.

O Societas Iesu Per universum...trás uma síntese visual da dispersão em escala planetária das missões dos jesuítas. Em cada continente, Scherer localiza a presença jesuítica com um círculo "iluminado" que contém o anagrama IHS, símbolo da Companhia de Jesus. São 73 ao todo, sendo 12 na América do Sul, 3 no Caribe, 9 na América do Norte, 9 na África, 19 na Europa, 15 na Ásia, 2 no Japão, mais 4 das Filipinas, Mindanau, Bornéu e Ilhas Marianas. O autor parece estar relativamente bem informado, ao menos quanto à América do Sul, pois trata de destacar as áreas onde a presença dos missionários encontrava-se em plena atividade e relativa expansão ao redor de 1700, como o caso da região platina, do Pampa e da Patagônia, e do Chile. A Amazônia, onde havia uma presença importante de missões, não possuí mais que um símbolo. E este está na área que corresponderia a Nova Granada. Já para a América do Norte chama a atenção a permanência da representação da Península da Califórnia como

${ }^{17}$ Langer, 2008: 79-109. 
uma ilha. Mas a precisão geográfica de rios, ilhas, penínsulas ou cadeias de montanhas não é o tema central deste mapa mundi. O real objetivo se revela nas alegorias do entorno. Além do cartucho de título, sustentado por querubins, há quatro alegorias que representam os quatro ícones da expansão da Companhia de Jesus nas quatro partes do mundo. Ignácio de Loyola, o fundador e centro de irradiação das ideias iniciais e dos princípios do jesuítismo; Francisco Xavier, o "Apóstolo" da Índia; André de Oviedo, o Patriarca da Etiópia; e José de Anchieta, o "Apóstolo" do Brasil. Para cada parte do mundo, um inspirador, um modelo, um agente da mundialização da ordem e da palavra de Cristo. Este mapa "é” a Companhia e sua Missão Mundo. Ao menos é o que Scherer pretendia que fosse visto no início do século XVIII.

Os três mapas citados dialogam em uma mesma direção. Se a Europa não está mais no centro, foi graças a ela e a seus navegadores que este mundo foi "revelado". Neste cenário terreno a luta final será travada em cada canto, até o triunfo da cristandade católica. E para esta luta Deus concedeu aos jesuítas o privilégio de serem os responsáveis de levar sua verdade à periferia, aos limites deste mundo. Assim, a projeção polar possibilita mapear a viagem de circunavegação de Magalhães, escamoteando o problema de quebra no roteiro visual que um Mapa Mundi tradicional provocaria. Permite, sobretudo, expressar a visão de mundo jesuítica. A evangelização jesuítica chega até a periferia do mundo que se imagina centralizado na Europa e no Mediterrâneo desde a Antiguidade. Mas os jesuítas provocam um deslocamento. Estão em todos os lugares. Nos limites antes desconhecidos. Mas estão conectados. São uma rede, que vai mais além da Europa. Realizam a tarefa universal do catolicismo. Como observou Protásio Langer, a cartografia de Scherer está prenhe de visões escatológicas e finalistas. Os jesuítas cumprem as escrituras em uma interpretação na qual a Parusia e o Juízo Final devem ser precedidos pelo anúncio da Boa Nova a toda a humanidade ${ }^{18}$.

Mas Heinrich Scherer pode ter sido o último, e um dos poucos jesuítas, a tentar esta síntese visual e cartográfica da dimensão mundial da Companhia de Jesus. Como bem aponta Protásio Langer ${ }^{19}$, Scherer era um "geógrafo de gabinete", que recebia as informações de seus pares espalhados pela orbe e as convertia em mapas gerais para seu Atlas. Longe iam os anos da Cosmografia e das descrições do mundo terreno e celeste ${ }^{20}$. Os cosmógrafo cediam lugar aos topógrafos e cartógrafos que "liam" os terrenos e relevos em escalas menores e locais. Os jesuítas espalhados por todas as frentes de evangelização contavam em suas fileiras com homens empenhados em novas tarefas no tocante a elaboração de mapas e descrições da geografia. O século XVIII será o século da corrida pelo estabelecimento do cálculo da Longitude ${ }^{21}$. E nesta corrida estarão em lados opostos os astrônomos, entre os quais perfilavam-se os jesuítas ${ }^{22}$, e os mecânicos, cujo desafio será desenvolver o relógio de precisão, glória que coube a John Harrison na segunda metade do século. Além disto, era preciso explorar, descrever, detalhar as regiões onde se encontravam as missões. Se pensarmos no caso americano, a ampla estrutura montada, sobretudo, a partir dos Colégios, Residências e Universidades, compreendia áreas com chácaras, fazendas, estâncias, além das reduções, denominação

\footnotetext{
${ }^{18}$ Ibíd.:88-89.

${ }^{19}$ Ibíd.: 81 .

${ }^{20}$ Lestringant, 2009.

${ }^{21}$ Sobel, 1996.

${ }^{22}$ Malhão Pereira, 2007-2008: 339-394.
} 
dos povoados indígenas com seus territórios. Era preciso determinar distâncias, demarcar rotas e caminhos, tornar precisos os limites de jurisdição e avançar. Avançar para áreas ainda não contatadas. Para populações ainda não evangelizadas. $O$ sobre todas estas tarefas, para as quais a cartografia se impunha como imprescindível, havia ainda que conviver com as disputas territoriais entre as coroas sob as quais os jesuítas se colocavam como súditos, apesar de sua alegada insegura fidelidade. Ir além dos limites conhecidos. E nestes limites, encontrar sociedades indígenas as quais se pretendia integrar a este mundo cristão e católico, ao mesmo tempo que se tratava de estender sobre elas a jurisdição colonial das monarquias. Tomo aqui a noção de limite, e não de fronteiras, em acordo com a proposição de Guilleume Boccara:

Sin embargo, considero que para caracterizar estos espacios resulta más apropiado el término de límite que el de frontera, porque el límite es cronológicamente y por lógica lo primero, en el sentido de que elementos que habitaban a los dos lados del límite son concebidos como heterogéneos y en la medida en que todo el trabajo de sometimiento consiste precisamente en transformar este límite en frontera $(. . .)^{23}$.

Será nestes limites, nestas periferias, que encontraremos alguns exemplos de jesuítas cartógrafos e seus mapas. Dois casos podem ser representativos e paradigmáticos de duas realidades distintas que poderiam reclamar a necessidade de uma cartografia da periferia do mundo católico e da empresa colonial. Um, demarcado no início do século XVIII. E outro nos estertores da presença da Companhia de Jesus na América. Um, no Oeste da Nova Espanha. Outro, nas ilhas meridionais da costa do Pacífico. Refiro-me aos padres Eusébio Kino e José Garcia. O primeiro, missionário na Pimería, Sonora e Califórnia. O segundo, missionário na ilha de Chiloé, na costa do Chile.

No século XVIII, o Noroeste da Nova Espanha ainda era uma região remota vista a partir da Cidade do México. A ampla área que se conecta a península da Califórnia era conhecida como Pimería e Sinaloa. Desde o século XVI a presença espanhola ainda não havia se imposto completamente sobre as comunidades indígenas. Sobretudo na Califórnia. A conquista espanhola desta região reservaria aos jesuítas um papel destacado na exploração e reconhecimento geográficos. Vasco Nuñez de Balboa revelara e denominara o Mar del Sur (Oceano Pacífico) em 1513. Esta revelação abriu novas possibilidades à expansão espanhola, e as expedições de busca por uma hipotética passagem que ligasse os dois oceanos tornaram-se freqüentes. Os interesses voltaram-se então para as alternativas na costa oeste da Nova Espanha. O objetivo claro e expresso dos espanhóis era o de alcançar as Índias pelo Mar del Sur, navegando a oeste. As tentativas realizadas ao longo do século XVI colocaram a Califórnia na geografia colonial espanhola. Mas sua conquista e colonização esteve envolta em um longo processo de promessas, fracassos e decepções, em várias etapas até o final do século $\mathrm{XVII}^{24}$. Por quase 150 anos, os espanhóis não haviam criado um estabelecimento fixo na Califórnia. Tampouco haviam realizado incursões ao interior, e os contatos com as populações indígenas foram, no mais das vezes, fortuitos. Do ponto de vista geográfico, pairavam ainda muitas dúvidas sobre a sua geografia, oscilando entre ilha ou península.

\footnotetext{
${ }^{23}$ Boccara, 2001: 08.

${ }^{24}$ Para um detalhamento das expedições e tentativas de colonização da Califórnia nos século XVI e XVII ver Del Río, 1990: 15-48.
} 
É neste contexto que se deve compreender o papel de Eusébio Kino, missionário jesuíta e cartógrafo. Ele fará parte das expedições que visavam ocupar a Califórnia e integrar sua população local. Em 1677, Kino integrará a expedição do Almirante Isidro de Atondo na tentativa de explorar e estabelecer núcleos povoadores na Califórnia. Kino recebeu três nomeações específicas para esta entrada à Califórnia: Reitor das missões que fossem fundadas, Vigário do Bispo de Guadalajara e Cosmógrafo Real ${ }^{25}$. Durante três meses, Eusébio Kino aproveitou as incursões para realizar observações geográficas. Mas a ocupação efetiva viu-se frustrada. A falta de água potável foi o fator determinante para a desistência de Atondo e seu retorno à outra margem do Golfo da Califórnia. Pouco mais de dois anos durara a estadia dos espanhóis na península. A escassa presença de rios e arroios e a aridez do solo convenceram o comandante a desistir da empresa $^{26}$.

O padre Kino elaborou, entre 1691 e 1696, em companhia dos padres Juan María Salvatierra e Juan Ugarte, um projeto de penetração na península, liderado e executado pelos missionários da Companhia de Jesus. As negativas foram constantes, tanto por parte das autoridades espanholas, como pelos superiores da ordem na Nova Espanha. Kino e Salvatierra realizaram então uma estratégia de duplo movimento. Enquanto Salvatierra lançava mão de todos os seus contatos políticos e eclesiásticos na defesa do projeto, Kino investia na fundação de reduções na região de Sonora, no noroeste da Nova Espanha ${ }^{27}$. Estas reduções, no entender de Kino, seriam responsáveis pelo abastecimento da missão evangelizadora da Califórnia ${ }^{28}$.

Durante dez anos, Kino estabeleceu uma rede de reduções na Pimería Alta, em Sonora. Nesta região, esboçou um projeto amplo de expansão missionária, no qual a Califórnia seria também uma etapa. Sua intenção era que, após assentadas as bases da Pimería Alta e da Califórnia, o avanço deveria prosseguir ao norte. A partir de 1697, concentrou-se em explorar uma rota até a costa, vinculada ao projeto de sustento das fundações na Califórnia. Sobretudo, porque neste ano, o Padre Salvatierra, cinco espanhóis e três índios cruzaram o golfo para dar início à evangelização da península. Deve-se a este grupo a fundação da primeira missão, chamada de Nuestra Señora de Loreto $^{29}$. A Kino coube a tarefa de seguir administrando as reduções de Sonora. Porém, permanecia com objetivo fixo de auxiliar as atividades na outra margem do Golfo. De suas explorações, resultaria a certeza de que a Califórnia tratava-se na realidade de uma península, e não uma ilha, como afirmado por muitos. $\mathrm{O}$ tema da peninsularidade da Califórnia foi, talvez, um dos agentes motores das explorações de Kino. Antes mesmo da primeira expedição de Atondo, Kino tinha em mente esta questão geográfica. Mas ainda compartilhava da opinião de que se tratava de uma ilha: “... me envían a la nueva conquista y nuevas misiones de las Californias, que, según mi parecer, es la mayor isla que tiene el orbe." 30 Mas, após as observações que pôde realizar sobre o terreno e as explorações realizadas entre 1687 e 1702, na Pimería Alta, passou a defender a peninsularidade da Califórnia:

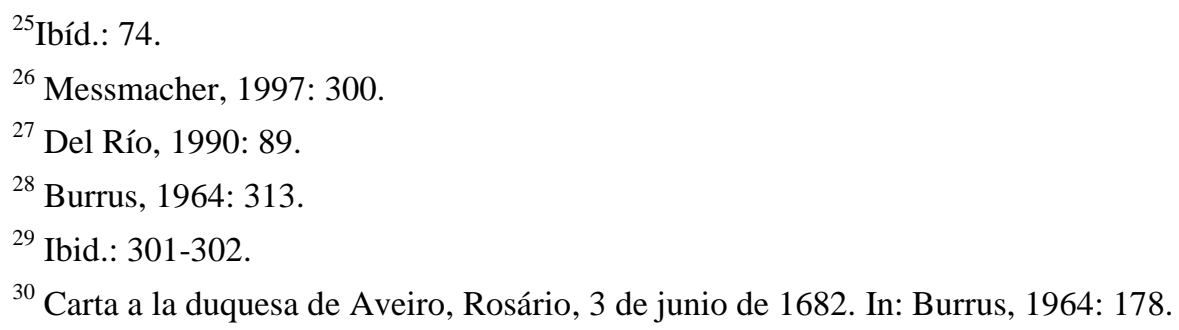


En esta creencia que la California era penisla y no isla, vine a estas Indias occidentales. Y assí que llegué a México por el P. provincial Bernardo Pardo fui señalado por missionero y cosmógrafo y rector de la California y procurando salir de las dudas que havia en las materias, mudé de parecer [...] porque otros muchos mapas y los más principales cosmógrafos modernos de Alemania, Flandes, Italia, Francia, etc., decían [...] que la California era isla [...], porque las muchas corrientes de norte a sur que experimenté en las navegaciones que hize en el brazo de California eran tan continuadas y a veces tan vehementes que parecía se comunicaba esta mar con la del norte; y me incliné a que la California era isla, y por tal la dibujé en algunos de mis mapas. Pero ahora, ya gracias a su Divina majestad, con varias y en particular con tres entradas de 150, de 170 y de 200 leguas que de aquí de Nuestra Señora de los Dolores en la actual Sonora al nortueste he hecho, he descubierto con toda individualidad, certidumbre y evidencia, con la abuja de marear y astrolabio en la mano, que la California no es isla sino penisla o istmo y que en 32 grados de altura ay passo por tierra a dicha California. ${ }^{31}$

Em 1702, durante sua última viagem ao Rio Colorado, Kino acreditou haver encontrado a passagem por terra até a Califórnia. Data desta época o Mapa del paso por tierra a la California y sus confinantes nuevas naciones y nuevas missiones de la Compañía de Jesús en la América Septentrional [Fig.3] ${ }^{32}$ Este mapa não é uma representação cartográfica de toda a península, mas sim apenas da região nordeste, destacando a comunicação com o continente ao norte do "Mar de la California". A única redução representada é a de Nuestra Señora de Loreto, embora em 1699 já houvesse sido fundada também a redução de San Xavier, a sudoeste de Loreto. Na realidade, o mapa procura localizar as reduções da Pimería Alta, área de maior atuação de Kino.

Os opositores de Kino encontravam-se na própria Companhia de Jesus, entre eles Agustín de Campos e Luis Velarde, que chegaram a planejar uma expedição dedicada a comprovar a insularidade da Califórnia, a qual nunca chegou a realizar-se ${ }^{33}$. Em apoio a Kino, o padre Juan Ugarte e o piloto inglês Willian Strafford navegaram em direção ao norte em 1721, confirmando a extremidade do Golfo e a comunicação com o continente $^{34}$. Em 1756, ainda permaneciam dúvidas sobre as idéias de Eusébio Kino. Quando o trabalho de revisão da obra de Venegas foi finalizado por Burriel, um conselheiro real ponderou que, no tocante à forma peninsular da Califórnia, o trabalho deixara a desejar ${ }^{35}$. A polêmica sobre a peninsularidade da Califórnia atravessou os séculos XVI, XVII e XVIII, sendo configurada em vários mapas dados a conhecer na Europa e na América, dentre os quais destacam-se os de Eusébio Kino.

\footnotetext{
${ }^{31}$ Kino, 1922: 157.

${ }^{32}$ Burrus, 1967, II: 13, mapa 31-

${ }^{33}$ Domingues, 2001: 05.

34 "Relación de descubrimiento del Golpho de California o mar lauretano, 1722", de Juan Ugarte.

Biblioteca Nacional, Fondo Californias, leg.53. In: Domingues, 2001: 05.

${ }^{35}$ Ibíd.: 06.
} 


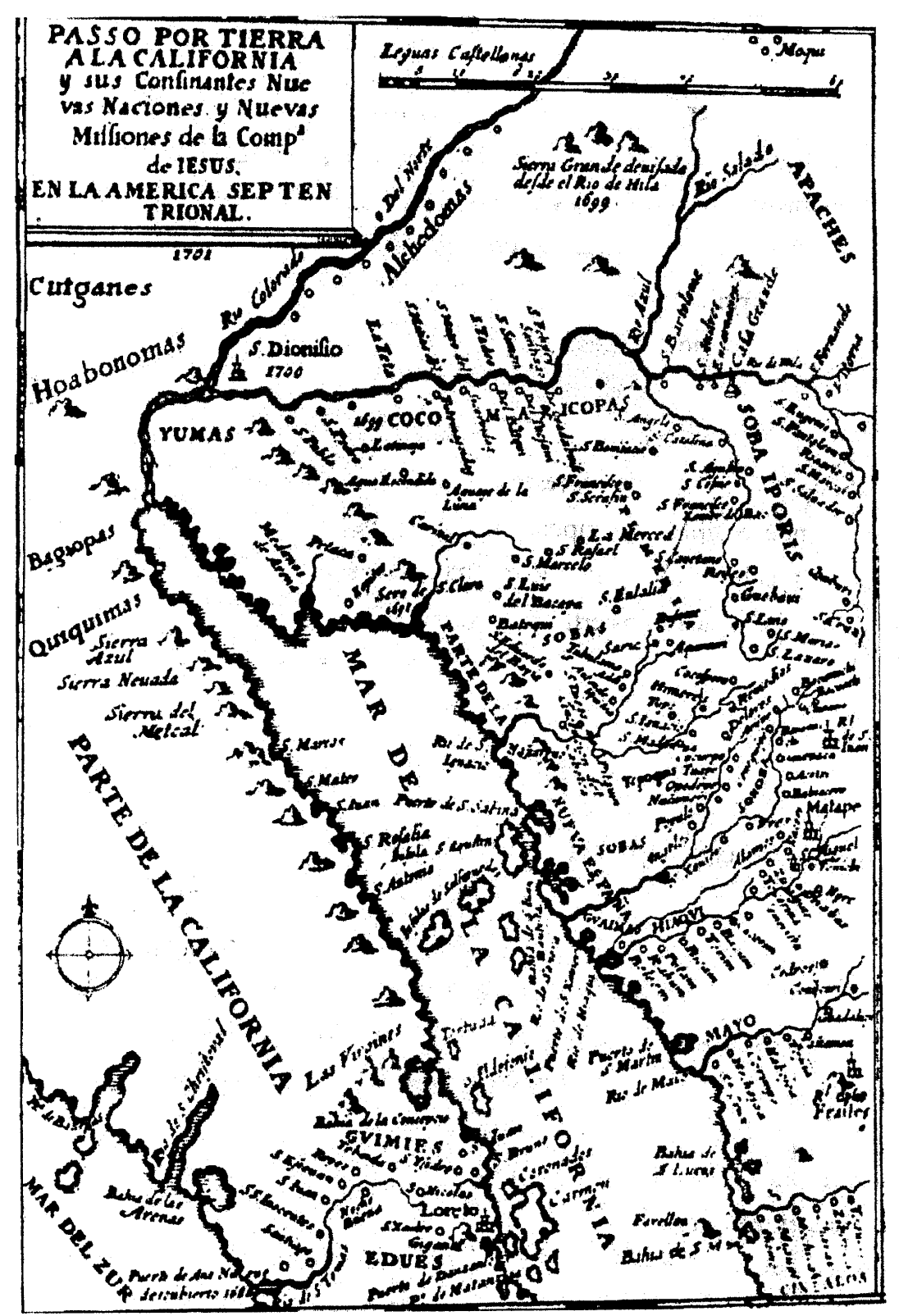

Fig. 3: Mapa del paso por tierra a la California y sus confinantes nuevas naciones y nuevas missiones de la Compañía de Jesús en la América Septentrional. Eusébio Kino, 1704.

Quase no outro extremo do continente, e sessenta e sete anos após as expedições de Kino, outro jesuíta se defrontava com um território ainda pouco explorado. E nele buscaria ampliar o número de conversos, ao mesmo tempo em que fazia o reconhecimento do terreno e sua geografia. A evangelização nas porções continentais do Chile apresentava resultados limitados, e o mesmo ocorria nos arquipélagos meridionais de Chiloé, Chonos e Guaitecas. O primeiro é composto pela Ilha Grande de Chiloé e outras menores como Cailín, Chaulinec e Alao. Os dois últimos, localizados ao sul de Chiloé, compreendem mais de duas mil ilhas e ilhotas situadas entre os $44^{\circ}$ e $47^{\circ}$ sul. Para alcançar as ilhas de Chonos e Guaitecas, os jesuítas partiam de Chiloé. A dificuldade de estabelecer assentamentos fixos nestas localidades distantes fazia com que os jesuítas optassem por deslocar os índios para ilhas mais próximas à Chiloé. Desde 1710, iniciaram algumas transferências de chonos das terras continentais 
contíguas aos arquipélagos para as ilhas desertas de Chaulinec e Atao. Conhecedores dos canais existentes entre as centenas de ilhas austrais, os chonos converteram-se em guias para as expedições de jesuítas. Em Cailín, instalou-se uma missão da qual partiam canoas para ilhas de Chonos e Guaitecas. É neste contexto que se desenvolve a expedição do padre José Garcia Martí. Esta viagem foi realizada entre outubro de 1766 e janeiro de 1767 e José Garcia registrou seu trajeto em um diário ${ }^{36}$. Através dele, sabese que intenção do jesuíta era recolher alguns indígenas para conduzir a missão de Cailín, cujo objetivo era: “... no solo para el cultivo espiritual de los neófitos que viven en la isla, sino también para procurar la conversión de los jentiles que viven mas hacia el sur $i$ estrecho de Magallanes...". 37 De Cailín partiram índios chonos canoeiros, que retornaram acompanhados de alguns caucahues do Golfo de Penas. Estas notícias animaram os jesuítas a tentar contatos diretos com os ilhéus dos arquipélagos. Em 23 de outubro de 1766, José Garcia partiu acompanhado de 34 índios caucahues e cinco espanhóis, distribuídos em cinco piráguas. Iniciava-se um percurso que duraria três meses.

Esta exploração, ainda que voltada para o aumento das conversões rumo ao Sul, permitia que fossem reconhecidas algumas regiões pouco ou nada frequentadas pelos agentes da colonização. E será um missionário jesuíta que acabará por descrevê-la e mapeá-la. No início do mês de novembro, a expedição já se encontrava no Canal Moraleda, situado entre as ilhas de Chonos e as ilhas e terras da costa meridional. Avançando sempre por este canal, José Garcia observou que se aproximava de um ponto sobre o qual havia imprecisões geográficas. A dúvida que perdurava era relativa à ligação entre os canais interiores e o Golfo de Guayneco, atual Golfo de Penas. Sobre esta questão, José Garcia observava que: “... los más prácticos dicen que a no ser canal, há de ser cortísimo el tramo intermedio de tierra i fácil para tirar las piraguas. También se sabe que desagua rio por la parte del sur i puede ser desague de la laguna em que acaba Aua [como denominava o canal]. Esto se debe averiguar para obviar el desecho de Ofqui." 38 José Garcia logo teria a oportunidade de verificar pessoalmente esta possibilidade. No dia 10 chegaram à laguna que se encontra na extremidade sul dos canais interiores, chamada Laguna San Rafael. Nela, José Garcia pôde visualizar os blocos de gelo desprendidos de um braço do Campo de Gelo San Valentin, que desemboca na laguna. No dia seguinte, montaram um acampamento na margem ocidental da laguna, ao qual José Garcia denominou Nuestra Señora de Mercedes. Encontravam-se sobre o Istmo de Ofqui, que o jesuíta pretendia atravessar, levando por terra três piráguas, para seguir a navegação por mar. Passado um mês e meio de viagem, foram avistados os primeiros sinais de presença dos indígenas locais, na forma de tendas feitas de ramos e galhos, além de ossos de lobos marinhos. Neste ponto, encontravam-se na extremidade norte do Canal Mesier, que atravessa todo o conjunto de ilhas ao sul dos $47^{\circ}$. Novamente, José Garcia refletiu sobre a geografia local, imaginando a possibilidade de uma ligação com o oceano Atlântico e a Baía de San Julian:

Poco mas adelante hallamos otras tres ramaditas en la boca i punta del norte del estero Mesier, famoso entre los indios, por no haberle hallado fin; tira al

\footnotetext{
${ }^{36}$ Garcia, 1889: 3-47.

${ }^{37}$ Ibid.: 3 .

${ }^{38}$ Ibíd. :12.
} 
este, $i$ se juzga cruce la cordillera, que por aqui es baja i quebrada; digna cosa de averiguarse allí por ver si es canal que cruce al mar del norte [Atlântico] $o$ alguna laguna, como por las muchas almas que se pueden lograr, i quizás puede comunicarse com la bahía San Julian, pues dicho estero está en la altura austral de $48 \operatorname{grados}^{39}$.

Após mais de dois meses de viagem, José Garcia lograva reunir apenas treze indígenas, os quais foram convidados a seguir até a missão de Cailín. Os poucos indígenas que conseguiu reunir relataram que haveria mais pessoas dispostas a acompanhá-lo se ele não houvesse tardado tanto em chegar àquelas ilhas. Garcia não ultrapassou os $48^{\circ}$ de latitude sul em sua expedição. Após cruzar o Istmo de Ofqui, agora em sentido contrário, o missionário, os soldados e os índios embarcaram na pirágua Nuestra Señora de Desamparados, e deram início ao retorno para Cailín, onde chegaram em 30 de janeiro de 1767. Garcia acrescentou em seu diário um balanço da expedição:

Ya el terreno está descubierto, la cosecha de almas en sazon; pues solo a la voz de que iba el misionero se juntaron muchas jentes, que al llegar pocos dias antes se hubieran logrado, pues quieren ser cristianos; [...] oh! quiera el cielo concedernos proporcionados médios para conquistar a Cristo estas naciones. Si hai españoles perdidos por el estrecho magallánico, este es el seguro medio de saberse. ${ }^{40}$

Uma visão otimista da continuidade de uma ação evangelizadora nos arquipélagos meridionais há poucos meses da expulsão dos jesuítas dos domínios da Espanha. Garcia produziu um diário e um mapa em cuja edição foi acrescentado o título Mapa construido por el P. Joseph Garcia de la Companía de Jesus año 1768 sacado de las observaciones hechas por el Sargento Mayor de Chiloe por los años de 1744 y por las observaciones hechas por el mismo Padre en dos viajes que hizo desde su Mission de Caylin en busca de gentiles en los años 1766 y 1767. [Fig.4] O diário foi publicado em quatro oportunidades. Em 1809, 1871, 1889 e 2011 ${ }^{41}$. E o mapa, além de acompanhar as edições anteriores do Diário, foi publicado uma vez mais em $2008^{42}$. Guarda e Jeria sustentam que as informações cartográficas constantes no mapa de Garcia se devem a informações retiradas de mapas anteriores que se extraviaram, não chegando até os dias atuais. O original de José Garcia também desapareceu, restando a cópia publicada por Murr em 1809.

O que há em comum entre Eusébio Kino e José Garcia? O fato de serem jesuítas cartógrafos cujas explorações serviram para que a geografia da América fosse traduzida aos conceitos e concepções dos europeus. Atuando nas periferias do Império espanhol, produziram cartografias periféricas que acabavam preenchendo os "vazios" dos mapas gerais e ampliando o espaço colonial. A cartografia jesuítica contribuiu para a organização colonial espanhola na América, definindo espaços, categorizando e reordenando as sociedades indígenas, demarcando zonas fronteiriças internas e externas,

\footnotetext{
${ }^{39}$ Ibíd.: 24.

${ }^{40}$ Ibíd.: 42.

${ }^{41}$ Ibíd., 1811, II: 506-599. 1871: 351-375. 1889: 3-47. 2011.

${ }^{42}$ Guarda y Moreno Jeria, 2008: 133.
} 
e continua a contribuir para uma outra interpretação das ações impetradas por agentes coloniais. Talvez esta seja também a maneira de compreender porque os rios Bermejo e Pilcomayo agora são apenas uma "realidade" geográfica e não podemos vê-los mais como o sangue de Tuvichavé e as lágrimas de Michiveva.

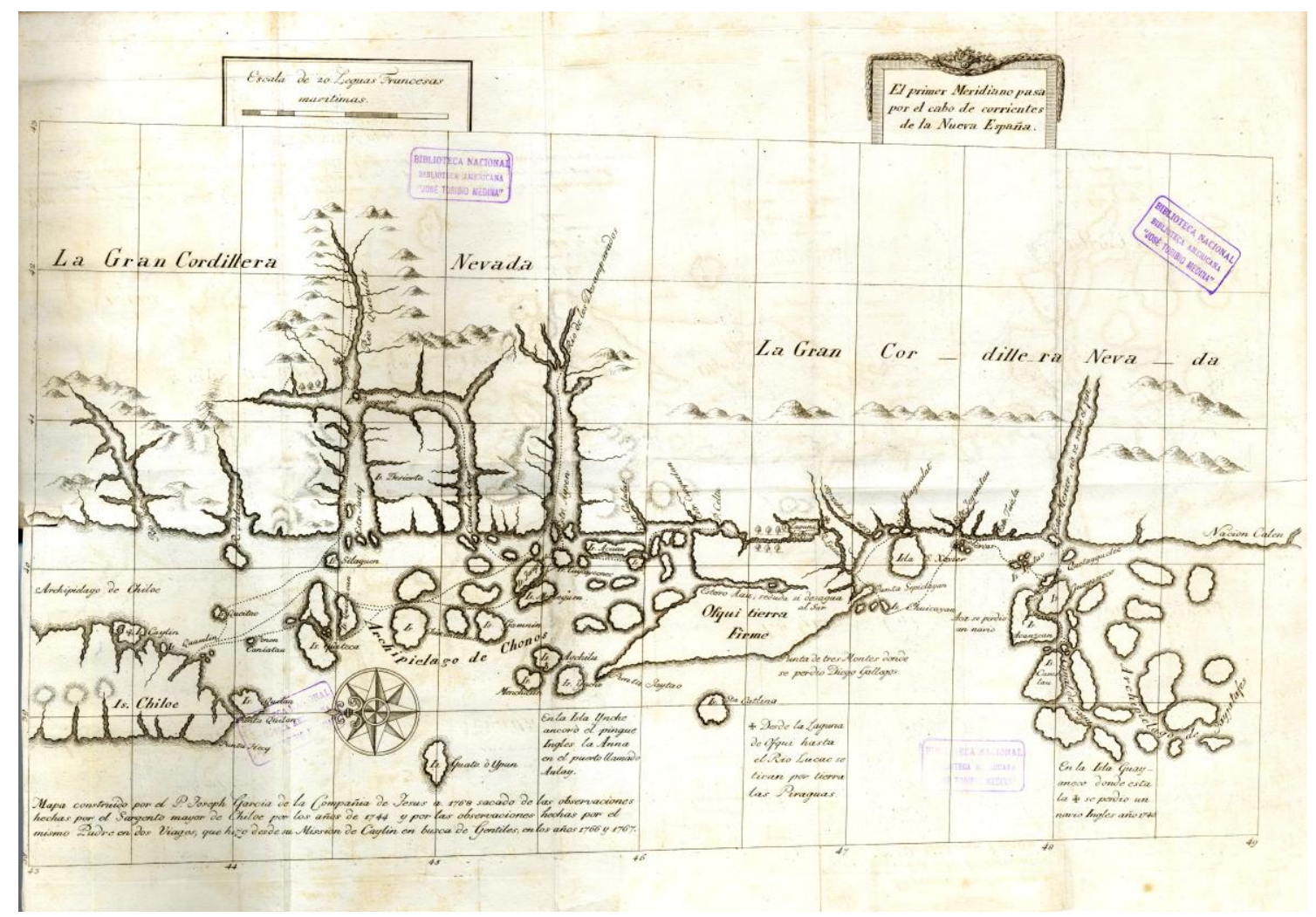

Fig.4: Mapa construido por el P. Joseph Garcia de la Companía de Jesus año 1768 sacado de las observaciones hechas por el Sargento Mayor de Chiloe por los años de 1744 y por las observaciones hechas por el mismo Padre en dos viajes que hizo desde su Mission de Caylin en busca de gentiles en los años 1766 y 1767.

\section{Referências}

Barcelos, A. H. F. (2013). O Mergulho no Seculum. Exploração, conquista e organização espacial jesuítica na América espanhola colonial. Porto Alegre: Ed. Animal.

Barnadas, J. M. (1997). A igreja católica na América espanhola colonial. In: Bethell, L. História da América Latina, v. I, Edusp, São Paulo.

Boccara, G. (2001). "Mundos nuevos en las fronteras del Nuevo Mundo". Revista Nuevo Mundo Mundos Nuevos. Debates, 2001. 
Bollandus, I. (1640) Imago primi saeculi Societatis Iesu a Provincia Flandro-Belgica eiusdem Societatis repraesentata. Amberes: Ex officina Plantiniana Balthasaris Moreti.

Boxer, C. R. (2007). A Igreja Militante e a Expansão Ibérica (1440-1770). São Paulo: Companhia das Letras.

Brasil de Sá, M. E. (2014). Jesuítas no Japão - Conflitos religiosos e a política do Sakoku. Revista Litteris n.14 Vol. 2. setembro.

Burrus, E. J. (1964). Kino escribe a la duquesa. Madrid: Colección Chimalistac, vol.18, Ediciones José Porrúa Turanzas.

(1967). La obra cartográfica de la Provincia Mexicana de la Compañía de Jesús (1567-1767). 2 vol. Colección Chimalistac, Madrid: Ediciones José Porrua Turanzas.

Cohen Shabot, L. e Martínez D’alòs-Moner, A. (2006). "The Jesuit Mission in Ethiopia (16th and 17th Centuries): an Analytical Bibliography". Aethiopica 9.

Del Río, I. (1990). A la diestra mano de las Índias. Descubrimiento y ocupación colonial de la Baja Califórnia. México D.F.: UNAM.

Diaz de Seabra, L. (2011). "Macau e os jesuítas na China (séculos XVI e XVII)". Revista História Unisinos. Vol. 15 N 3 - setembro/dezembro.

Domingues B. H. (1999). "A Filosofia e Ciência Modernas nos Escritos do Padre Simão de Vasconcelos". Numen: Revista de estudos e pesquisa da religião. Vol.2, N.2, UFJF, Juiz de Fora, pp. 105-139.

(2001). "Natureza, Religião e política nos escritos de Miguel Venegas sobre as missões jesuítas da Baixa Califórnia". MNEME Revista de Humanidades, v.2, n.4, Jun/Jul. pp.01-17.

Eisenberg, J. (2000). As missões jesuíticas e o pensamento político moderno. Encontros culturais, aventuras teóricas. Belo Horizonte: Editora UFMG.

Garcia. J. (1811). Diario del viaje i navegación hechos por el Padre José García de la Compañía de Jesús, desde su misión de Cailín, en Chiloé, hacia el sur, en los años 1766 i 1767. En: Nachrichten von verschiedenen Ländern des spanischen Amerika: Ed. Christoph Gottlieb von Murr. Halle: Christian Hendel, vol. 2.

(1871). Diario del viaje i navegación hechos por el padre José García de la Compañía de Jesus desde su misión de Cailin, en Chiloé, hacia el sur en los años 1766 y 1767. Anales de la Universidad de Chile, Nov.

(1889). Diario del viaje i navegación hechos por el padre José García de la Compañía de Jesus desde su misión de Cailin,en Chiloé, hacia el sur en los 
años 1766 y 1767. Anuario Hidrográfico de la Marina de Chile. Valparaíso, Instituto Hidrográfico de la Armada de Chile, Vol. 14.

(2011). Misión por lo canales autrales: la travesía de un jesuíta desde Chiloé hacia laguna San Rafael. Prólogo de Rodrigo M. Jeria y Introducción de Diego Barros Arana. Ofquí Editores, Temuco.

Gruzinski, S. (2001). "Os mundos misturados da monarquia católica e outras connected histories”. Revista Topoi, Vol.2, N.2, Jan-Jun., UFRJ, Rio de Janeiro.

(2010). Las quatro partes del mundo. História de una mundialização. México: FCE.

Guarda, G. y Moreno Jeria, R. (2008). Monumenta cartographica chiloensia: misión, territorio y defensa, 1596-1826. Santiago: Corporación Amigos del Patrimonio Cultural de Chile.

Kino S.J. E. F. (1922). Las Misiones de Sonora y Arizona: Comprendiendo la crónica titulada Favores Celestiales y relación diária de la entrada al noroeste. Edición de Francisco Fernández del Castillo. México D.F.: Archivo General e la Nación Vol. VIII. Editorial Cultura.

Laucouture, J. (1994). Os Jesuítas. 1. Os Conquistadores. Porto Alegre: L\&PM Editora.

Langer, P. (2008). Cartas geográficas edificantes: o imaginário da conversão dos povos indígenas nos mapas dos jesuitas Heinrich Scherer e Samuel Fritz. São Bernardo do Campo: Nanduti Editora.

Lestringant, F. (2009). A Oficina do Cosmógrafo: ou a Imagem do Mundo no Renascimento. Civilização Brasleira, Rio de Janeiro.

Loyola, I. de (1997). Constituições da Companhia de Jesus e normas complementares. São Paulo: Edições Loyola.

Malhão Pereira, J. M. (2007-2008). "Um manuscrito de cerca de 1767, do P. José Monteiro da Rocha S.J. com uma solução matemática para a obtenção da longitude pelas distâncias lunares". Cuadernos de Estudios Borjanos.

Manning, P. W. (2007). “La emblemática jesuítica en El Criticón”. Revista eHumanista. Volume 9.

Messmacher, M. (1997). La búsqueda del signo de Dios: ocupación jesuita de la baja California. México: Fondo de Cultura Económica.

O`Malley, J. W. (2004). Os Primeiros Jesuítas. São Leopoldo: RS: Ed. UNISINOS..

Parodi, L. (2005). Leyendas Indígenas de la Argentina. Buenos Aires: Ediciones Andrómeda. 
Scherer, H. (1702-1710). Atlas novus exhibens orbem terra queum per naturae opera, historiae novae ac veteris monumenta, artisquae geographicae leges et praecepta : hoc est, geographia universa in semptem partes contracta. 7 vols.

Sobel, D. (1996). Longitude: the True Story of a Lone Genius Who Solved the Greatest Scientific Problem of His Time. Viking Penguin.

Wright, J. (2006). Os Jesuítas: missões, mitos e histórias. Rio de Janeiro: Relum e Dumará. 